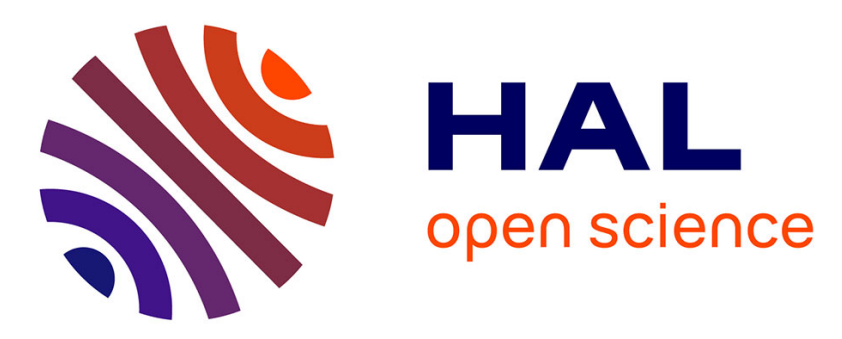

\title{
Impact of shear stress and impeller design on the production of biogas in anaerobic digesters
}

Aline Lebranchu, Stéphane Delaunay, Philippe Marchal, Fabrice Blanchard, Stéphane Pacaud, Michel Fick, Eric Olmos

\section{- To cite this version:}

Aline Lebranchu, Stéphane Delaunay, Philippe Marchal, Fabrice Blanchard, Stéphane Pacaud, et al. Impact of shear stress and impeller design on the production of biogas in anaerobic digesters. Bioresource Technology, 2017, 245, pp.1139 - 1147. 10.1016/j.biortech.2017.07.113 . hal-03346395

\section{HAL Id: hal-03346395 \\ https://hal.science/hal-03346395}

Submitted on 16 Sep 2021

HAL is a multi-disciplinary open access archive for the deposit and dissemination of scientific research documents, whether they are published or not. The documents may come from teaching and research institutions in France or abroad, or from public or private research centers.
L'archive ouverte pluridisciplinaire HAL, est destinée au dépôt et à la diffusion de documents scientifiques de niveau recherche, publiés ou non, émanant des établissements d'enseignement et de recherche français ou étrangers, des laboratoires publics ou privés. 


\title{
IMPACT OF SHEAR STRESS AND IMPELLER DESIGN ON THE PRODUCTION OF BIOGAS IN ANAEROBIC DIGESTERS
}

Aline LEBRANCHU ${ }^{1,2}$, Stéphane DELAUNAY $Y^{1,2}$, Philippe MARCHAL ${ }^{1,2}$, Fabrice BLANCHARD $^{1,2}$, Stéphane PACAUD ${ }^{3}$, Michel FICK ${ }^{1,2}$, Eric OLMOS ${ }^{1,2, *}$

\footnotetext{
${ }^{1}$ CNRS, Laboratoire Réactions et Génie des Procédés, UMR 7274, 2 avenue de la forêt de Haye, TSA 40602, Vandœuvre-lès-Nancy, F-54518, France.

${ }^{2}$ Université de Lorraine, LRGP, UMR 7274, 2 avenue de la forêt de Haye, TSA 40602, Vandœuvre-lès-Nancy, F54518, France.

${ }^{3}$ ENSAIA, Université de Lorraine, 2 avenue de la forêt de Haye, TSA 40602, Vandœuvre-lès-Nancy, F-54518, France.

*eric.olmos@univ-lorraine.fr
}

Keywords: Mixing, helical ribbon, CFD, biogas, anaerobic digestion

\begin{abstract}
Today, intensification of anaerobic digestion is still a scientific and technical challenge. The present study proposed combined experimental and computational fluid dynamics numerical approaches to characterize the impact of shear stress and impeller design on the biogas production after sequential additions of substrate. Liquid phase (cattle manure digestate) rheological law was experimentally determined and input in computational fluid dynamics simulations. The results showed that the original use of a double helical ribbon in digester allowed a significantly faster dispersion of fresh substrate than the use of a classical Rushton turbine, leading to a $50 \%$ higher methane production rate. However, with both impellers, too high agitation rates entailed a clear slow-down of production rate and a decrease in $\mathrm{CH}_{4}$ content. To avoid this loss of productivity, it was shown that the maximal value of shear stress,
\end{abstract}


determined by computational fluid dynamics simulations, was a consistent parameter to set the upper agitation conditions in digesters.

\section{1- Introduction}

Anaerobic digestion of wastes or substrates is a highly bioenergy production process as the involved biochemical and physical mechanisms are not yet clearly understood, making bioreactor design, set-up and control still not fully optimized. Indeed, the rheology of the substrates, such as cattle manure, is generally considered as non-newtonian which addresses the real mixing performance of the digesters today available, a fortiori of large-scale systems. Then, an inadequate mixing may promote temperature or concentration gradients $(\mathrm{pH}$, substrates, and dissolved gases) within the digester that may possibly impact biological reactions, substrate availability, dissolved gases stripping, the spatial distribution of microbial populations and in fine the performance of biogas production (composition, flow rate). Therefore, the characterization of mixing in digesters is of key importance to establish reliable and robust relationships between mixing performance and the efficiency of biogas microbial synthesis.

Several studies dealing with the impact of mixing on the biogas production rate have been published these last years, using various designs of impellers and vessels or process scales. Nevertheless, as the different results obtained in these articles do not systematically agree one with each other, it remains difficult to draw generalizable trends regarding this impact. For instance, Hoffmann et al. (2008) used a 4.5 L digester equipped with an axial flow impeller. They showed that a high agitation, obtained by increasing the agitation rate only, had no effect on biogas production in steady-state regime while intense mixing (1500 rpm) had a negative impact on the digester performance during initial startup. Lastly, Kaparaju et al. (2008) used a

3.6 L digester equipped with impellers whose geometry was not specified and also 
demonstrated that minimal intermittent mixing of liquid phase (10 min mixing prior to feeding) enabled a higher biogas production than a continuous mixing.

Rheological behavior and bioreactor hydrodynamics are key parameters to characterize when mixing effects are studied. Cattle manure, which is the substrate used in the present study, is a relatively viscous feedstock which is often used for anaerobic digestion, especially in farm facilities. This fluid is known to reveal a complex rheological behavior (Chen, 1986) entailing that dramatic viscosity gradients are likely to occur in digester if the shear rate distribution is not sufficiently homogeneous. Rheology of cattle manure is non-newtonian, with a shearthinning behavior (Achkari-Begdouri and Goodrich, 1992; Chen, 1986; El-Mashad et al., 2005). To model cattle manure rheology, a power-law model $\left(\mu=K \cdot \dot{\gamma}^{n-1}\right)$ relating the liquid viscosity $\mu(\mathrm{Pa} \mathrm{s})$, the shear rate $\dot{\gamma}\left(\mathrm{s}^{-1}\right)$, the flow index $n(-)$ and the consistency index $K\left(\mathrm{~Pa} \mathrm{~s}^{\mathrm{n}}\right)$ is thus often used. In parallel to the determination of the liquid phase rheology, it is also necessary to develop and use robust approaches allowing the prediction of the spatial distribution of velocity gradients and thus viscosities and shear stresses. Mixing and hydrodynamics characterization of anaerobic digesters and more generally of bioreactors operating with non-newtonian fluids have been previously studied using Computational Fluid Dynamics (CFD) simulations. This approach relies on the 3D simulation of the liquid velocity fields with possible complex rheology homogenized by moving parts or not. In most of the anaerobic digesters involving cattle manure or sludge digestion, a mechanical agitation is generally preferred. One or several propellers can be used to stir the liquid phase at different frequencies (Bridgeman, 2012; Wu, 2012a, Wu2012b). With this choice of stirrers, a cavern may also be observed around it due to stress gradients (Low et al., 2012), which entail the existence of dead-zone whose volume could reach almost $50 \%$ of total volume (Bridgeman, 2012). All these studies have thus suggested that classical stirrers, such as Rushton turbine or 
even axial flow impellers, may probably not be the best choice to obtain an adequate mixing of the broth.

Finally, it is noticeable that studies describing biogas production performance in characterized digester hydrodynamics are still seldom in literature as these two approaches were generally used separately. In the present study, anaerobic digestions were performed to (i) highlight the impact of mixing on the biogas production using cattle manure as bacterial consortium and cellulose as substrate, (ii) to determine the transient behavior of the digester after substrate feeding. For this purpose, the biogas productions (total gas flow rate and composition) obtained after sequential additions of cellulose were measured in a 2 L digester mixed either by a Rushton turbine or a double helical ribbon and compared. To get further insight the differences obtained between both systems, the rheological behavior of the cattle manure and digestate were determined and CFD simulations were conducted to finely characterize the liquid phase hydrodynamics.

\section{2- Material and methods}

\subsection{Biogas production}

Two 2 L digesters (liquid height: $130 \mathrm{~mm}$; total height: $200 \mathrm{~mm}$; diameter: $136 \mathrm{~mm}$ ) were designed and built to compare biogas production with different mixing devices (experimental set-up is described in Figure 1). The first one is mixed with a non-standard double helical ribbon (height $130 \mathrm{~mm} / \mathrm{step} 130 \mathrm{~mm} /$ width $11.6 \mathrm{~mm}$ ) equipped with two scrapers at its bottom. The second digester was mixed by a standard 6-bladed Rushton turbine with height and width of the blades: $12 \times 12 \mathrm{~mm}$ and total diameter $D$ of $45 \mathrm{~mm}$. These reactors were equipped with a $\mathrm{pH}-\mathrm{rH}$ probe (Mettler, Ohio, USA) and a manometer (Leo Keller-druck, Winterthur, Schweiss) to measure the reactor pressure. The gas exit was equipped with a condenser to remove water 
vapor, a gas-counter for the measurement of total biogas production (Ritter, Bochum, Germany) and an online micro-gas-chromatography (SRA, Lyon, France) containing 2 modules with 2 columns and 2 thermal conductivity detectors (TCD). The first column is a molecular sieve preceded by a divinyl benzene ethylene glycol-dimethylacrylate polymer column (poraplotU) with a backflush system avoiding the introduction of $\mathrm{CO}_{2}$ in the molecular sieve. This first module determined $\mathrm{H}_{2}, \mathrm{O}_{2}, \mathrm{~N}_{2}, \mathrm{CH}_{4}$ concentrations while the second one is a single poraplot $\mathrm{U}$ measuring $\mathrm{CO}_{2}$ and $\mathrm{H}_{2} \mathrm{~S}$ concentrations.

During the biogas production, the temperature was regulated at $40{ }^{\circ} \mathrm{C}$ by a heated jacket. The broth was mixed at agitation rates of 10,50 or $90 \mathrm{rpm}$ for the helical ribbon and 22, 66 or $110 \mathrm{rpm}$ for the Rushton turbine to independently study, for each agitator, the impact of this parameter on biogas production. The raw matter was composed of $2 \mathrm{~L}$ of digestate from cattle manure digestion obtained from the 'La Bouzule' farm (Laneuvelotte, France). After grinding, the TS content of the digestate was $8.8 \%$. A mass of $14 \mathrm{~g}$ of cellulose was also regularly added each time the biogas flowrate became lower than $30 \mathrm{~mL} \mathrm{~h}^{-1}$. During the culture and for each cellulose addition, several parameters were measured: the delay time $\tau$ between addition time and the beginning of the induced biogas production, the production duration, the maximal production flowrate and biogas composition. The time-averaged biogas flowrate between two additions of cellulose $\bar{Q}$ and the total volume of biogas produced $V$ were also determined.

\subsection{Rheological study}

The rotational rheometer used during this work consisted in a helical ribbon placed in a cylindrical vessel with a volume of $785 \mathrm{~mL}$ (height: $100 \mathrm{~mm}$; diameter: $100 \mathrm{~mm}$ ) made in Plexiglas. The ribbon was connected to a motor with a rotation frequency (Lamy Rheology, Lyon, France). The helical ribbon used had the following dimensions: height $100 \mathrm{~mm}$; diameter $980 \mathrm{~mm}$; width of ribbon $10 \mathrm{~mm}$ and step $100 \mathrm{~mm}$. 
The first step of the rheological study was to determine the stirrer characteristics (power dissipation and shear rate). In laminar regime (approximately $\mathrm{Re}<10-100$ ), power dissipation is given by the following relation, linking the Reynolds number Re and the power number Np:

$$
N_{p}=\frac{P}{\rho \cdot N^{3} \cdot D^{5}}=\frac{K_{p}}{R e}
$$

$$
\text { with } R e=\frac{\rho \cdot N \cdot D^{2}}{\mu}
$$

With $N\left(\mathrm{~s}^{-1}\right)$ the agitation rate, $\rho\left(\mathrm{kg} \mathrm{m}^{-3}\right)$ the density of fluid, $\mu$ (Pa s) the liquid viscosity, $D$ (m) the diameter of the stirrer, and $P(\mathrm{~W})$ the experimental power obtained with the equation 3.

$$
P=2 \pi \cdot N \cdot C
$$

With $C(\mathrm{~N} \mathrm{~m})$ the experimental torque obtained on the stirrer.

The value of the $K_{P}$ constant depends on the design of the impeller. Whereas for the Rushton turbine, the value $K_{p}=75$ could be taken from literature data (Rushton et al., 1950), the value of the constant for the non-standard helical ribbon used in the present study had to be experimentally determined. To do this, newtonian solutions of glycerol at different concentrations $(100 \%, 85 \%, 75 \% \mathrm{w} / \mathrm{v})$ and water were used and the torque was measured at various agitation frequencies imposed by the rheometer to obtain the power curve $N_{p}=f(R e)$. The $K_{P}$ value was then determined by modelling the laminar part of this curve.

Secondly, as the digestate may show a shear-thinning rheology, it is also necessary to determine the apparent viscosity $\mu_{a}$ and thus the apparent shear rate $\dot{\gamma}_{a}$ within the digester. To calculate this mean shear rate, the Otto-Metzner method (Metzner and Otto, 1957), that supposes a linear relationships between $\dot{\gamma}_{a}$ and $N$ in laminar regime, was applied:

$$
\dot{\gamma}_{a}=k_{s} . N
$$


The Otto-Metzner constant $k_{s}$ mainly depends on impeller geometry. For the Rushton turbine, $k_{s}=11.5$ was obtained from literature data (Metzner et al., 1961) while the constant for the helical ribbon was obtained from the Couette analogy (Aït-Kadi et al., 2002). The apparent viscosity $\mu_{a}$ is defined as the viscosity calculated at the apparent shear rate $\dot{\gamma}_{a}$ :

$$
\mu_{a}=K \cdot \dot{\gamma}_{a}^{n-1}
$$

The apparent Reynolds number $\mathrm{Re}_{\mathrm{a}}$ is determined considering the preceding apparent viscosity:

$$
R e_{a}=\frac{\rho \cdot N \cdot D^{2}}{\mu_{a}}
$$

Following the Otto-Metzner approach, $\mathrm{Re}_{\mathrm{a}}$ could be experimentally determined by analogy with Newtonian fluids mixing, substituting Re by $\mathrm{Re}_{\mathrm{a}}$ in equation 1 . Once the values of constants $K_{P}$ and $k_{s}$ obtained, rheology study was performed on grinded digestate. The temperature in the rheometer was regulated at $40{ }^{\circ} \mathrm{C}$ using a heated jacket. From the measured torque at a given rotating frequency the consistency $K$ and flow index $n$ of grinded digestate could be determined.

\subsection{CFD simulations of digester hydrodynamics}

In this work, CFD simulations were performed using the commercial CFD software ANSYS Fluent 16.0. The geometry of the digester was sketched using ANSYS Design Modeler and ANSYS Meshing was used to divide the geometry into calculations cells, allowing the discretization of the transport equations. The mesh was non-conformal and was composed of 277748 and 283474 tetrahedral cells for the digesters equipped with the helical ribbon and the Rushton turbine respectively. The hydrodynamics of each agitation condition used experimentally was numerically simulated.

\subsubsection{Transport equations}


Navier-Stokes transport equations were solved in transient regime. The rotation of the impeller was modelled using a Sliding Mesh approach, which offers intrinsically a better precision than Multiple Reference Frame in the case of slowly-rotating impellers. As mentioned before, a power-law was used to model the rheological behavior of digestate and, considering the value of the Reynolds numbers (Table 1A and Figure 2), laminar flow was supposed. Thus transport equations stated as follows:

Continuity equation

$\nabla \cdot \mathbf{u}=0$

Momentum equation

$\rho \frac{\partial \mathbf{u}}{\partial t}+\rho \nabla \cdot(\mathbf{u} \cdot \mathbf{u})=-\nabla p+\nabla \cdot \boldsymbol{\sigma}+\rho \mathbf{g}$

The viscous stress tensor $\boldsymbol{\sigma}$ was given by:

$$
\boldsymbol{\sigma}=\mu\left(\nabla \mathbf{u}+\nabla \mathbf{u}^{T}\right)
$$

$\mu(\mathrm{Pa} \mathrm{s})$ is the local viscosity determined at the local shear rate $\dot{\gamma}, \mathbf{u}$ the liquid velocity $\left(\mathrm{m} \mathrm{s}^{-1}\right)$, $\boldsymbol{\sigma}$ is the shear stress $(\mathrm{Pa})$ and $\rho$ was set to $1000 \mathrm{~kg} \mathrm{~m}^{-3}$.

\subsubsection{Volume-averaged quantities}

The volume-averaged velocity magnitudes and dynamic viscosities over the total liquid volume $V_{L}$ were respectively obtained by:

$$
\langle\|\mathbf{u}\|\rangle=\frac{1}{V_{L}} \iiint_{V_{L}}\|\mathbf{u}\|(V) \mathrm{d} V ;\langle\mu\rangle=\frac{1}{V_{L}} \iiint_{V_{L}} \mu(V) \mathrm{d} V ;\langle\sigma\rangle=\frac{1}{V_{L}} \iiint_{V_{L}} \mu(V) \cdot \dot{\gamma}(V) \mathrm{d} V
$$

\subsubsection{Determination of mechanical power}


In order to quantify and compare performances of mixing with helical ribbon and Rushton turbine, power dissipation and mixing times have been determined for each experiment. Power dissipation quantifies the power transferred by the stirrer to the liquid phase, further dissipated by viscous friction, which prevails in laminar regime. The mechanical power transferred to the liquid phase was calculated by:

$$
P_{C F D}=2 \pi N C_{C F D}
$$

With $P_{C F D}(\mathrm{~W})$ the power transmitted by the impeller to the fluid, $N\left(\mathrm{~s}^{-1}\right)$ the agitation rate and $C_{C F D}(\mathrm{~N} \mathrm{~m})$ the calculated torque on the stirrer.

\subsubsection{Mixing time}

The mixing time $t_{M}$ was determined by the method previously described by Allonneau et al. (2015). A sphere (radius $r=5 \mathrm{~mm}$ ) of inert tracer with properties identical to liquid phase was initially patched in the computational domain; its convective-diffusive dispersion was calculated using:

$$
\rho \frac{\partial Y}{\partial t}+\nabla \cdot(\rho \mathbf{u} Y)=-\nabla \cdot \boldsymbol{J}
$$

With $Y$ the local mass fraction of tracer, and $\mathbf{J}$ the diffusive mass transport given by the Fick's law:

$$
\boldsymbol{J}=-\rho D_{i f f} \nabla Y
$$

The molecular diffusivity $D_{\text {iff }}$ was set to $10^{-15} \mathrm{~m}^{2} \mathrm{~s}^{-1}$. After the injection, the tracer concentration was numerically recorded at a point located near the lateral wall of reactor at 4 $\mathrm{mm}$ from the bottom of the reactor. The $95 \%$ mixing time was determined by identifying the time beyond which the concentration $c$ at the probe point remained in the range $[0.95\langle c\rangle ; 1.05$

$\langle c\rangle]$ with $\langle c\rangle=\frac{M_{0}}{V_{L}}=9 \times 10^{-3} \mathrm{~g} \mathrm{~L}^{-1}$ is the volume-averaged concentration based on the mass 
of tracer $M_{0}$ initially introduced in the digester. The energy required to obtain homogeneity in the reactor $E_{\text {homogeneity }}$ was also determined by the equation 14 .

$$
E_{\text {homogeneity }}=P_{C F D} \cdot t_{M}
$$

\subsubsection{Numerical solving parameters}

The time step used for the simulations was set at a value of $0.01 \mathrm{~s}$, which corresponded to angular displacements of the impeller between 0.6 and 6.6 degrees. This value allowed the convergence of transport equations solving within less than 20 iterations at each time step. Pressure-velocity coupling was solved using a SIMPLE algorithm and $2^{\text {nd }}$ order UPWIND numerical schemes were used for the discretization of the momentum and species transport equations. The time-averaged velocity distributions were obtained by time-averaging instantaneous velocities over a sufficiently long time, characterized by stabilized mean local velocities over time.

\section{3- Results and discussion}

\subsection{Biogas production}

The successive additions of cellulose in the two digesters provided the biogas production given in Figure 3A while the applied steps of agitation rate are given in Figure 3B. The values of agitation rate chosen for each step were $a$ priori chosen to obtain comparable values for mean and maximal shear stresses for each configuration, allowing a more robust comparison of both systems. Each addition was followed by a transient peak of biogas production. These results clearly showed that, in some cases, the stirrer design and the agitation rates had an impact on biogas production rate. Indeed, the averaged values of biogas flowrate between two additions

ranged from 123 to $175 \mathrm{~mL} \mathrm{~h}^{-1}$ for the digester equipped with the helical ribbon while these 
values were only around $82 \mathrm{~mL} \mathrm{~h}^{-1}$ for the digester equipped with the Rushton turbine (Table 1A). Considering the same total process duration of $1440 \mathrm{~h}$ approximately, the total volume of biogas produced in the digester mixed by the ribbon was finally $50 \%$ higher than in the digester with the Rushton turbine (159 L for the ribbon; $106 \mathrm{~L}$ for the Rushton). The performance differences observed between the two devices could be explained by the lag between each addition of cellulose and the start-up of biogas production peak. Indeed, as shown in Figure 4 and Table 1A, production begun after a longer time (approximately $70 \mathrm{~h}$ ) when the Rushton turbine was used in comparison with the digester using the helical ribbon (approximately $10 \mathrm{~h}$ ). However, it is also important to note that, in the range of agitation rates studied, while this onset time was weakly dependent of agitation rate for the helical ribbon, no impact could be identified for the Rushton impeller (Table 1A).

Moreover, when considering the digester involving the helical ribbon, it could be noticed that the lower the mixing frequency, the higher and the thinner the peak of flowrate and the lower the biogas flowrate is (Table 1A). On the contrary, with the Rushton turbine, these trends were observed only at $10 \mathrm{rpm}$. When analyzing the composition of biogas at the end of each production peak, it can also be noted that for the bioreactor mixed by the helical ribbon, the agitation rates of 50 and $90 \mathrm{rpm}$ entailed a significant decrease of $\mathrm{CH}_{4}$ content from 64 (value measured at $10 \mathrm{rpm}$ ) to $57 \%$. For the bioreactor using the Rushton turbine a similar decrease from $64 \%$ (value measured at 22 and $66 \mathrm{rpm}$ ) to $59 \%$ was observed at an agitation rate of 110 rpm (Table 1A). The negative effects of agitation rate on biogas production were also in agreement with the results of Kaparaju et al. (2008) who showed higher biogas production with intermittent mixing than with strong continuous mixing. It is however important to note that a change of impeller design may significantly impact these effects and no data concerning the design of the impellers used were provided by Kaparaju et al. (2008). To explain this, one hypothesis would be the impact of liquid-gas mass transfer. From a theoretical point of view, 
the gas-liquid mass transfer coefficient is independent of the gas considered. Thus it could be stated that an increase of agitation rate and thus of the $\mathrm{k}_{\mathrm{L}}$ a value might promote the stripping of all dissolved gases, whatever their nature. Consequently, the direct impact of $\mathrm{k}_{\mathrm{L} a}$ increase would be an increase of total biogas flowrate. This seems to indicate that liquid-gas mass transfer is not responsible for the biogas flowrate variation.

$\mathrm{pH}$ on-line monitoring, which can bring valuable information regarding microbial kinetics and gas transfers in the digester, were also reported in Figure 3C for both agitation devices. A focus on combined production of biogas and $\mathrm{pH}$ variations is also proposed for a $200 \mathrm{~h}$ process duration for remarkable agitation conditions (Figure 4). First, a transitory increase in pH was measured when the cellulose was added; this increase was more pronounced in the case of the helical ribbon. As the addition needed the opening of the digester and thus suddenly modified the gas-liquid equilibrium in the digester, this increase could probably be explained by a $\mathrm{CO}_{2}$ stripping from the liquid phase. As mixing was expected more efficient in the digester mixed by the helical ribbon, the liquid-gas mass transfer coefficient was also probably improved, leading to more pronounced and more sudden stripping of $\mathrm{CO}_{2}$ and thus to the $\mathrm{pH}$ variations observed. After this small increase, a sudden decrease of approximately $0.3 \mathrm{pH}$ unit was observed in both digesters; this decrease was concomitant with the onset of the biogas production peak. Minimal values of $\mathrm{pH}$ were also concomitant with the maximal values of biogas flowrate (Figure 4). This decrease could be related to an accumulation of acids produced by acidogenesis and acetogenesis reaction steps. Finally, the progressive exhaustion of these acids explained the increase in $\mathrm{pH}$ up to a value close to the initial one, before next cellulose addition.

An important result is that noticeable differences were measured in $\mathrm{pH}$ variations according to the mixing frequency applied. Indeed, for the highest agitation rates (namely 50 and $90 \mathrm{rpm}$ for the helical ribbon and $110 \mathrm{rpm}$ for the Rushton turbine), a significantly more progressive $\mathrm{pH}$ 
increase was observed during the production peak (Figure 4C and 4D). Moreover, the profiles obtained at low agitation rates (10 rpm for helical ribbon, 22 and $66 \mathrm{rpm}$ for the Rushton turbine) were similar one from each other and characterized by rapid increase of $\mathrm{pH}$ back to its initial value, before cellulose addition (Figure 4A and 4B). Muhammad Nasir et al. (2017) showed too that increasing the Reynolds number leads to a decrease in biogas production rate in an oscillatory flow anaerobic reactor. A Reynolds number around 100 and 300 give high biogas performance compare with no agitation or agitation at Reynolds number of 500. They explain the higher performance by improving the concentration in volatiles fatty acids in a safe range and explain the inhibition at too high Reynolds number by disruption of syntrophic relationship between microorganisms. The increase in volatiles fatty acids concentrations is not in accordance with the results in figure $3 \mathrm{~B}$ showing that $\mathrm{pH}$ minimum values are higher at high mixing frequencies. However the present results are closer with those of Lindmark et al. (2014) who found similar or higher VFA concentrations at lower mixing intensities.

To get further insight into the physical mechanisms implied in the phenomena observed and described previously, it is thus necessary to characterize more finely the digester hydrodynamics.

\subsection{Digester hydrodynamics characterization}

\subsubsection{Rheological behavior of cattle manure digestate}

The experimental measurements of cattle manure digestate rheology have confirmed its shearthinning behavior of this liquid phase. The best fit of experimental data was obtained with a power law model and the following values for consistency and flow index were obtained:

$$
\mu=4.90 \cdot \dot{\gamma}^{-0.68}
$$


The comparison of these results with the equations of Achkari-Begdouri (1992) showed significant discrepancies for the flow consistency $\left(K=0.74 \mathrm{~Pa} \mathrm{~s}^{0.4}\right)$ and flow index $(n=0.4)$. These differences may be explained by the liquid phase pretreatment. Indeed, whereas AchkariBegdouri (1992) used sieved manure, cattle manure was grinded in the present study. No yield stress or viscoelastic behavior were also put into evidence by rheological measurements on the digestate, on the contrary to the measurements of Baudez et al. (2013) but these authors did not consider any substrate pretreatment. These two comparisons reminded the impact of pretreatments on broth rheology, and thus mixing performance of the digester, and confirmed the limits of generalizing literature data for liquid phase rheology.

First, laminar regime was verified for each agitation conditions using impeller power curves (Figure 2) and the a posteriori determination of $\mathrm{Re}_{\mathrm{a}}$ values (Table 1A). These values remained respectively lower than 10 and 100 for the Rushton turbine and the helical ribbon. From the experimental measurements obtained, the impeller constant $K_{p}$ was found to be $K_{p}=383$ for the helical ribbon used in this study (Figure 2) and the value provided by the Couette analogy for the Otto-Metzner constant was $k_{S}=42$. These values were close to the values for relatively similar helical ribbons $\left(K_{p}=273\right.$ (Ho and Kwong, 1973) and $k_{s}=30$ (Nagata et al., 1971)) ; the differences observed between both values may be explained by the bottom scrapers added to the ribbon used in the present study.

\subsubsection{Numerical simulation of digester hydrodynamics}

Numerical simulations were first validated by comparing the power numbers determined by numerical simulations and rheology experiments (Figure 2). It can be noted that the agreement between both determinations was quite satisfactory for all the agitation conditions studied, which confirmed the robustness of the numerical approach. The mean velocity and viscosity fields are also presented on Figure 5 for the six agitation conditions while global mixing 
characteristics obtained by CFD, namely, volume averaged velocity magnitude, volume averaged dynamic viscosities, mixing time and total energy to obtained homogenization are given in Table 1B.

Hydrodynamics simulations of the digester equipped with the Rushton turbine revealed a large unmixed zone, whatever the agitation rate, characterized by near-zero velocities and viscosities reaching the zero-shear viscosity (approximately $10 \mathrm{~Pa} \mathrm{~s}$ ). At an agitation rate of $110 \mathrm{rpm}$, this zone, also generally called 'cavern', existed for radial coordinates $r>1.5 \mathrm{~cm}$ from the blades extremity and spread to the wall of the reactor. This flow behavior was already experimentally observed by Low et al. (2012) in a vessel mixing a fluid mimicking sludge rheology using a Rushton turbine. In the zone surrounding the impeller (i.e $r<1.5 \mathrm{~cm}$ from the blades), higher shear rates were encountered, which resulted in a significant decrease in broth viscosity till 0.22 Pa s and increase of liquid velocities till $0.2 \mathrm{~m} \mathrm{~s}^{-1}$. The volume-averaged velocity determined in the whole digester volume was $\langle u\rangle=0.0041 \mathrm{~m} \mathrm{~s}^{-1}$. A brief outlook to the CFD results obtained for the bioreactor equipped with the helical ribbon operating at an agitation rate of 10 rpm revealed dramatic changes in the homogenization performances (Table 1B and Figure 5). Indeed, the maximal and volume-averaged velocities were found equal to $0.034 \mathrm{~m} \mathrm{~s}^{-1}$ and 0.02 $\mathrm{m} \mathrm{s}^{-1}$ respectively, which corresponded to a 5 times increase in comparison with the Rushton turbine operating at $110 \mathrm{rpm}$. Thanks to a better homogeneity of the velocity field, the volumeaveraged viscosity at the preceding agitation rates was significantly lower for this digester design $(\langle\mu\rangle=5.2 \mathrm{~Pa} \mathrm{~s})$ than for the design involving Rushton turbine $(\langle\mu\rangle=9.3 \mathrm{~Pa} \mathrm{~s})$. To compare both systems, the definition of 'dead zones' proposed by Bridgeman (2012) may also be used. This author proposed to reference as dead the zones in which velocities remained lower than $5 \%$ of the highest velocity. Considering this definition, the critical values of liquid velocities were found to be $0.001 \mathrm{~m} \mathrm{~s}^{-1}$ and $0.0017 \mathrm{~m} \mathrm{~s}^{-1}$ for the bioreactors respectively equipped with the Rushton turbine rotating at an agitation rate of $110 \mathrm{rpm}$ and the helical ribbon 
rotating at an agitation rate of $10 \mathrm{rpm}$. Using these values, it could be shown that $91 \%$ of the volume of the reactor equipped with Rushton were dead zones, while this value dramatically dropped to less than $1 \%$ in the case of the digester using the helical ribbon. Till now, the use of helical ribbons in a digester was not referenced in literature. However, the results obtained clearly showed that it could limit the fraction of dead zones in comparison with digesters whose hydrodynamics was described in the literature, for instance the ones mixed by gas recirculation (Karim et al., 2004 ; Latha et al., 2009 ; Vesvikar and Al-Dahhan, 2005), by liquid recirculation (Wu and Chen, 2008), or mechanically mixed by Rushton turbine (Low et al., 2012). Lastly, in the case of digestate showing yield stresses, the use of helical ribbon should also be recommended (Paul et al., 2004) and its benefits on liquid homogenization performance would probably be amplified in comparison with turbines or propellers, thanks to a limitation in cavern occurrence. Using the simulated velocity fields, the mixing time was numerically determined for each of the six digester configurations. For both stirrers and as expected, mixing time decreased with the increase in agitation rates with values between $20 \mathrm{~s}$ and $190 \mathrm{~s}$ in the vessel mixed by the ribbon and between $2800 \mathrm{~s}$ and $11700 \mathrm{~s}$ for bioreactor mixed by the Rushton turbine (Table 1B). It could be also noticed that a constant $\left(N \cdot t_{M}\right)$ product (dimensionless mixing time) with values of 34 and 4600 approximately for the ribbon the Rushton turbine respectively were obtained for all configurations, which should be classically obtained in mixing vessels. It is also important to note that, for the two configurations showing a similar power dissipation (helical ribbon at $10 \mathrm{rpm}$ and Rushton turbine at $110 \mathrm{rpm}$ ) the ratio $\left(t_{M, \text { ribbon }} / t_{M, \text { turbine }}\right)$ reached a value of 15 . This difference could be explained by the zerovelocities in the region of cellulose addition, restricting mass transport to diffusive mass transport only.

Lastly, the results showed that the total energy required to obtain liquid homogenization $E_{\text {homogeneity }}$ was systematically lower with the ribbon than with the Rushton turbine (Table 1B), 
even for similar power dissipation. This clearly showed the great potential of helical ribbons use in digesters, both from the minimization of homogenization times and consumed energy points of view.

\subsection{Impact of hydromechanical stress on biogas production}

The numerical characterization of bioreactor hydrodynamics can be used to discuss the variabilities of biogas production and composition observed experimentally from one configuration to each other. Indeed, the delayed onset of biogas production observed experimentally after each cellulose addition in the bioreactor equipped with the Rushton turbine could probably be related to the higher mixing times determined by CFD simulations. Considering that the homogenization of cellulose was significantly slower with the Rushton turbine, its availability for the micro-organisms was also slower, entailing the delay of biogas production. In particular, while the experimental ratios of production delay times $\tau_{\text {turbine }} / \tau_{\text {ribbon }}$ were found equal to 7 approximately, the ratio of mixing times was of the same order of magnitude (approximately 15). However, it is also important to note that, quantitatively, the delay times of biogas production were two orders of magnitude higher than the mixing times, indicating that homogenization performance was probably not the sole phenomenon explaining the difference in biogas production profiles. First, this difference could be explained by the fact that the numerical tracer added in the CFD study was considered as liquid. Thus the determination of mixing time did not consider a possible solubilization duration, expected experimentally. Moreover, microbial cellulose hydrolysis and consumption could probably begin before its complete homogenization in the bioreactor, imposing a third characteristic time in the system. Indeed, the kinetic constant of cellulose degradation was found to be about $1.25 \mathrm{~d}^{-1}$ (Noike et al., 1985) leading to a characteristic degradation time of about $1 / 1.25=0.8$ day, which was significantly higher than the mixing time numerically 
determined. This suggested that, once the cellulose was dispersed, biogas production followed cellulose degradation and thus promoted similar biogas production rate for all configuration with the Rushton turbines. Hoffmann et al. (2008) and Karim et al. (2005) showed that mixing at high intensity had negative effects during the initial startup, which may seem not in total agreement with the present results. However, it was also showed that mixing should rather be considered in terms of homogenization capacities rather on mixing intensity or only power dissipation. Indeed, these mixing properties should be carefully used in the case of bioreactors operating with caverns and important dead zones, namely with turbines or propellers, due to significant viscosity gradients. Our results showed that high mixing performances were necessary to begin the biogas production earlier and so to increase biogas production performances.

Despite the positive impact of helical ribbon use for production onset, a clear negative impact of agitation rate was also observed on the organic acids consumption as shown by the slower increase of $\mathrm{pH}$, spreader peak of biogas production and lower $\mathrm{CH}_{4}$ content at the highest agitation rates of 50 and $90 \mathrm{rpm}$ (Figure 4, Table 1A). In anaerobic digesters, $\mathrm{pH}$ variations mainly result from the accumulation and the consumption of the organic acids synthesized during acidogenesis and acetogenesis and consumed during methanogenesis.

Following conclusions of Conrad et al. (1985), Dolfing (1992) and Whitmore et al. (1987), Hoffman et al. (2008) explained the negative effects of agitation rate on the biogas flowrate by the disruption of microbial flocs, which disadvantaged syntrophic relationships. Using metagenomic analysis, Yang et al. (2017) demonstrated that shearing had a noticeable effect on microbial population, by improving diversity and evenness at intermediate shearing. However, these authors also showed that high level of shearing decreased microbial diversity in the digester. In a fluidized bed, Kundu et al. (2014) showed that microbial community structure was negatively impacted by hydrodynamic shear for liquid vertical velocities higher than $6 \mathrm{~m}$ 
$\mathrm{h}^{-1}$. If this assumption of possible floc disruption is made here, this break-up phenomenon should be mainly related to the shear stress encountered in the bioreactor. The CFD simulation results provided values of the volume-averaged shear stress $\langle\sigma\rangle=5.4,9.1$ and $11 \mathrm{~Pa}$ (equation 10) for the helical ribbon operating respectively at agitation rates of 10,50 and $90 \mathrm{rpm}$ while $\langle\sigma\rangle$ was only 1.3 and $1.6 \mathrm{~Pa}$ for the Rushton turbine rotating at 66 and $110 \mathrm{pm}$ respectively. Considering the maximal values of shear stress, which is also commonly used to characterize floc breakage (Henzler, 2000), the values obtained were roughly $\sigma_{\max }=26,46$ and $52 \mathrm{~Pa}$ for the helical ribbon rotating at 10, 50 and $90 \mathrm{rpm}$ and $\sigma_{\max }=25$ and $29 \mathrm{~Pa}$ for the Rushton turbine at 66 and $110 \mathrm{rpm}$ respectively. Thus, the process conditions that promoted similar $\mathrm{pH}$ and biogas production peaks (helical ribbon rotating at $10 \mathrm{rpm}$ and Rushton turbine rotating at 66 rpm) were also conditions for which the maximal shear stress were close (26 vs $25 \mathrm{~Pa}$ ). For higher maximal shear stresses $\left(\sigma_{\max }>30 \mathrm{~Pa}\right)$, a slower acid consumption and lower $\mathrm{CH}_{4}$ contents were measured. This suggests that, regarding the physical mechanisms characterized by CFD simulations, floc disruption or at least an impact of shear stresses on biogas production is consistent with the present results. Generalizing the maximal shear stress of $30 \mathrm{~Pa}$ approximately as a critical value impacting biogas production rate would be speculative. Similarly, in wastewater treatment process, Jiang et al. (2016) have recently shown that an increase in shear rate above $5 \mathrm{~s}^{-1}$ provoked an abrasion of the anaerobic sludge granules and, as a consequence, a decrease of biogas flowrate and $\mathrm{CH}_{4}$ content. Thus, it could be clearly advised to firstly estimate the value of shear stress before designing anaerobic digesters, especially the impeller type and rotation frequency.

\section{4- Conclusion}


The present study proposed combined experimental and CFD numerical approaches to characterize the impact of shear stress and impeller design on biogas production. These results demonstrated that the use of helical ribbon in digesters, which is original in literature, was particularly adapted when rapid dispersion of fresh substrates was looked for. The helical ribbon allowed a $50 \%$ higher methane production rate than the Rushton turbine with less energy consumption for substrate dispersion. It has been also demonstrated that maximal shear stress was a robust parameter for digester design to avoid the slow-down of methane production rate, observed at highest agitation rates.

\section{Acknowledgments}

The authors would like to thank the French government (Programme Investissements d'Avenir) and ADEME for their financial support. 


\section{References}

[1] Achkari-Begdouri, A., Goodrich, P.R., 1992. Rheological properties of Moroccan dairy cattle manure. Bioresour. Technol. 40, 149-156.

[2] Aït-Kadi, A., Marchal, P., Choplin, L., Chrissemant, A.-S., Bousmina, M., 2002. Quantitative Analysis of Mixer-Type Rheometers using the Couette Analogy. Can. J. Chem. Eng. 80, 1166-1174.

[3] Allonneau, C., Olmos, E., Guyot, S., Ferret, E., Gervais, P., Cachon, R., 2015. Hydrodynamic characterization of a new small-scale reactor mixed by a magnetic bar. Biochem. Eng. J. 96, 29-37.

[4] Baudez, J. C., Gupta, R. K., Eshtiaghi, N., Slatter, P., 2013. The viscoelastic behaviour of raw and anaerobic digested sludge: strong similarities with soft-glassy materials. Water Res, 47, 173-180.

[5] Bridgeman, J., 2012. Computational fluid dynamics modelling of sewage sludge mixing in an anaerobic digester. Adv. Eng. Softw., 44, 54-62.

[6] Chen, Y.R., 1986. Rheological properties of sieved beef-cattle manure slurry: Rheological model and effects of temperature and solids concentration. Agric. Wastes 15, 17-33.

[7] Conrad R, Phelps TJ, Zeikus JG. 1985. Gas metabolism evidence in support of the juxtaposition of hydrogen-producing and methanogenic bacterial sewage sludge and lake sediments. Appl Environ Microbiol 50:595-601.

[8] Dolfing J. 1992. The energetic consequences of hydrogen gradients in methanogenic ecosystems. FEMS Microbiol Ecol 101:183-187

[9] El-Mashad, H.M., van Loon, W.K.P., Zeeman, G., Bot, G.P.A., 2005. Rheological properties of dairy cattle manure. Bioresour. Technol. 96, 531-535.

[10] Henzler, H. J. 2000. Particle stress in bioreactors. In Influence of Stress on Cell Growth and Product Formation (pp. 35-82). Springer Berlin Heidelberg. 
[11] Ho, F.C., Kwong, A., 1973. Guide to designing special agitators. Chem. Eng. 80, 94-104.

[12] Hoffmann, R.A., Garcia, M.L., Veskivar, M., Karim, K., Al-Dahhan, M.H., Angenent, L.T., 2008. Effect of shear on performance and microbial ecology of continuously stirred anaerobic digesters treating animal manure. Biotechnol. Bioeng. 100, 38-48.

[13] Jiang, J., Wu, J., Poncin, S., Li, H. Z., 2016. Effect of hydrodynamic shear on biogas production and granule characteristics in a continuous stirred tank reactor. Process Biochem, $51,345-351$.

[14] Kaparaju, P., Buendia, I., Ellegaard, L., Angelidakia, I., 2008. Effects of mixing on methane production during thermophilic anaerobic digestion of manure: lab-scale and pilotscale studies. Bioresour. Technol. 99, 4919-4928.

[15] Karim, K., Hoffmann, R., Thomas Klasson, K., Al-Dahhan, M.H., 2005. Anaerobic digestion of animal waste: Effect of mode of mixing. Water Res. 39, 3597-3606.

[16] Karim, K., Varma, R., Vesvikar, M., Al-Dahhan, M.H., 2004. Flow pattern visualization of a simulated digester. Water Res. 38, 3659-3670.

[17] Kundu, K., Bergmann, I., Klocke, M., Sharma, S., Sreekrishnan, T. R., 2014. Influence of hydrodynamic shear on performance and microbial community structure of a hybrid anaerobic reactor. J Chem Technol Biot, 89, 462-470.

[18] Latha, S., Borman, D.J., Sleigh, P.A., 2009. CFD multiphase modelling for evaluation of gas mixing in an anaerobic digester [WWW Document]. URL http://eprints.whiterose.ac.uk/10314/ (accessed 4.22.15).

[19] Lindmark, J., Eriksson, P., Thorin, E., 2014. The effects of different mixing intensities during anaerobic digestion of the organic fraction of municipal solid waste. Waste management, 34, 1391-1397.

[20] Low, S., Parthasarathy, R., Slatter, P., Eshtiaghi, N., 2012. Hydrodynamics study sludge in anaerobic digesters. Chem. Eng. Trans. 29, 1321-1326. 
[21] Metzner, A.B., Feehs, R.H., Ramos, H.L., Otto, R.E., Tuthill, J.D., 1961. Agitation of viscous Newtonian and non-Newtonian fluids. AIChE J. 7, 3-9.

[22] Metzner, A.B., Otto, R.E., 1957. Agitation of non-Newtonian fluids. AIChE J. 3, 3-10.

[23] Muhammad Nasir, I., Ghazi, M., Idaty, T., Omar, R., Wan Abd Karim Ghani, W. A., 2017. Anaerobic Batch Digestion of Cattle Manure under Various Oscillatory Flow Mixing. Pertanika J Sci Technol, 25.

[24] Nagata, S., Nishikawa, M., Tada, H., Gotoh, S., 1971. Power consumption of mixing impellers in pseudoplastic liquids. J. Chem. Eng. Jpn. 4, 72-76.

[25] Noike, T., Endo, G., Chang, J.-E., Yaguchi, J.-I., Matsumoto, J.-I., 1985. Characteristics of carbohydrate degradation and the rate-limiting step in anaerobic digestion. Biotechnol. Bioeng. 27, 1482-1489.

[26] Paul, E. L., Atiemo-Obeng, V. A., Kresta, S. M., 2004. Handbook of industrial mixing: science and practice. John Wiley \& Sons, Hoboken, New Jersey.

[27] Rushton, J. H., Costich, E. W., Everett H. J., 1950. Current power characteristics of mixing impellers. Chem. Eng. Prog. 46, 395-404.

[28] Vesvikar, M.S., Al-Dahhan, M., 2005. Flow pattern visualization in a mimic anaerobic digester using CFD. Biotechnol. Bioeng. 89, 719-732.

[29] Whitmore TN, Lloyd D, Jones G, Williams TN. 1987. Hydrogen-dependent control of the continuous anaerobic digestion process. Appl Microbiol Biotechnol 26:383-388.

[30] Wu, B., Chen, S., 2008. CFD simulation of non-Newtonian fluid flow in anaerobic digesters. Biotechnol. Bioeng. 99, 700-711.

[31] Wu, B., 2012a. Large eddy simulation of mechanical mixing in anaerobic digesters. Biotechnol. Bioeng. 109, 804-812.

[32] Wu, B., 2012b. Computational Fluid Dynamics Study of Large-Scale Mixing Systems with Side-Entering Impellers. Eng. Appl. Comput. Fluid Mech. 6, 123-133. 
[33] Yang, S., Phan, H. V., Bustamante, H., Guo, W., Ngo, H. H., Nghiem, L. D., 2017. Effects of shearing on biogas production and microbial community structure during anaerobic digestion with recuperative thickening. Bioresource Technol, 234, 439-447. 
Figure 1

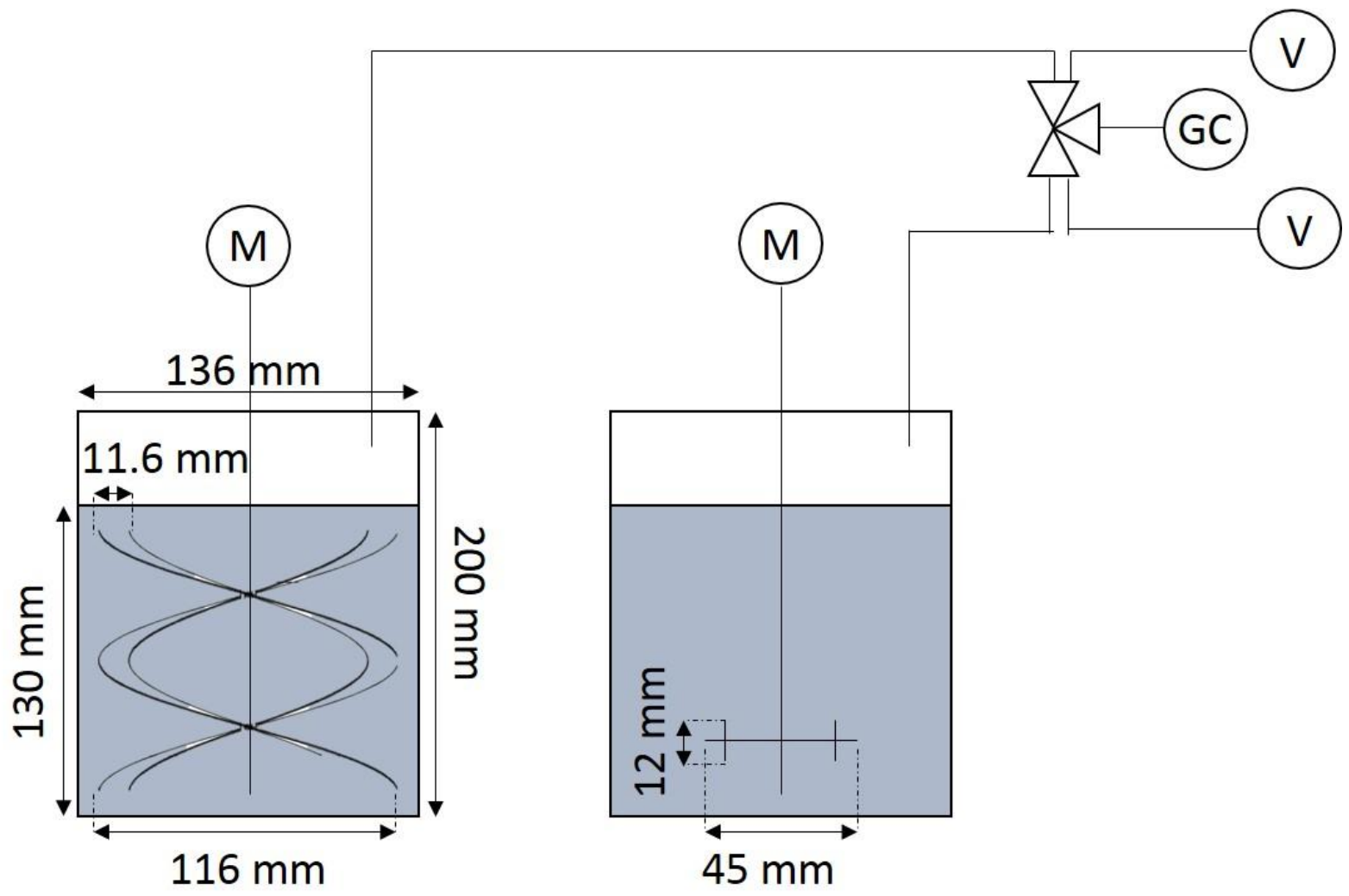

Figure 1: Experimental setup. Digester equipped with the helical ribbon (on the left) and with the Rushton turbine (on the right). M: Motor; GC: Gas chromatography; V: Gas Counter. 
Figure 2

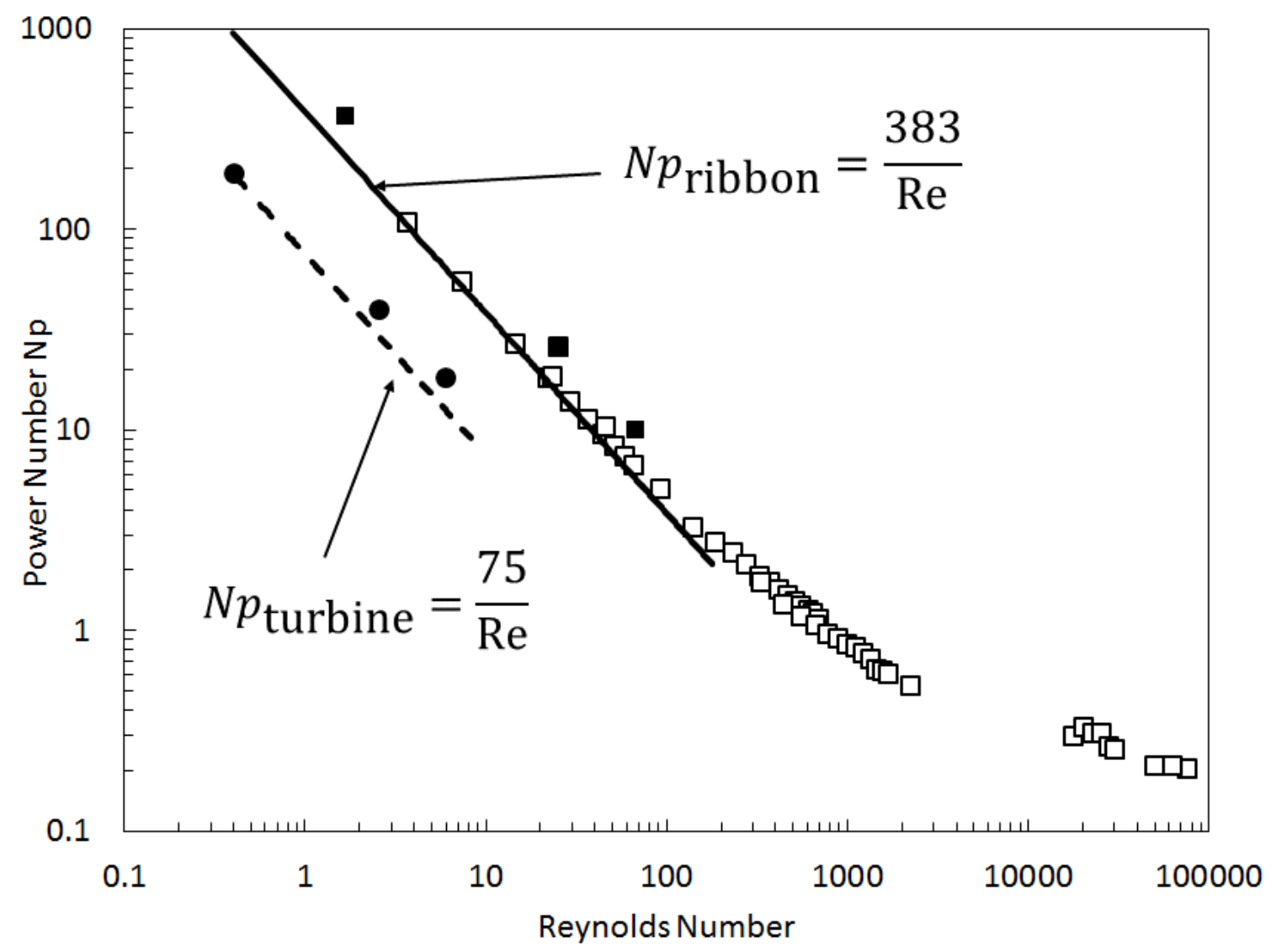

Figure 2: Experimental (open symbols) and numerical (closed symbols) determination of power curves $\mathrm{Np}=\mathrm{f}(\mathrm{Re})$ in the digester equipped with the Rushton turbine $(\bullet)$ and the helical ribbon $(\mathbf{\square})$. 
Figure 3

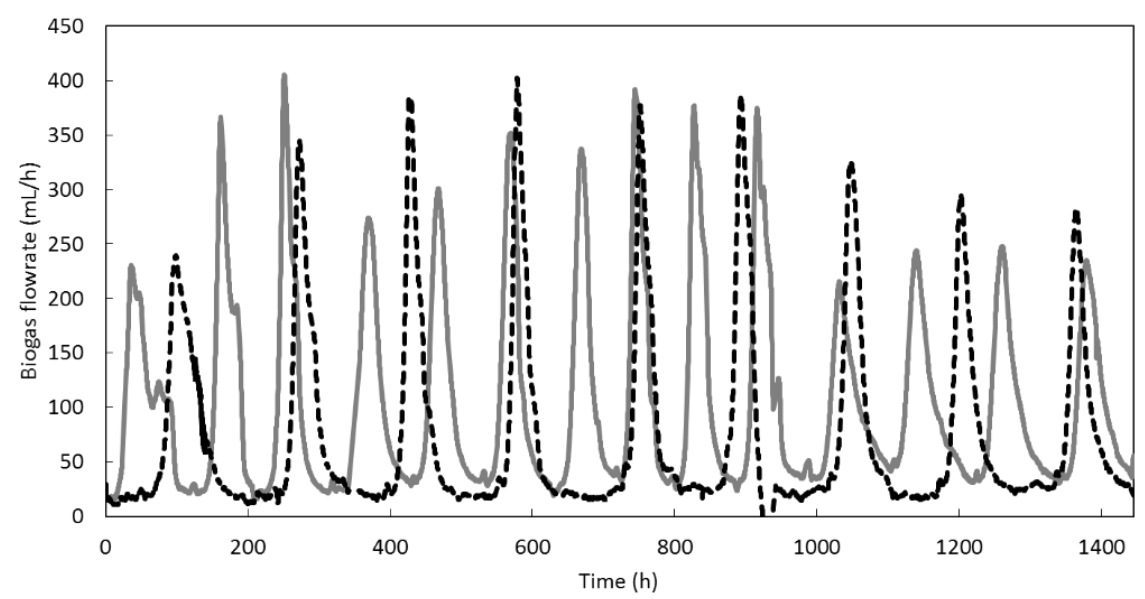

(A)

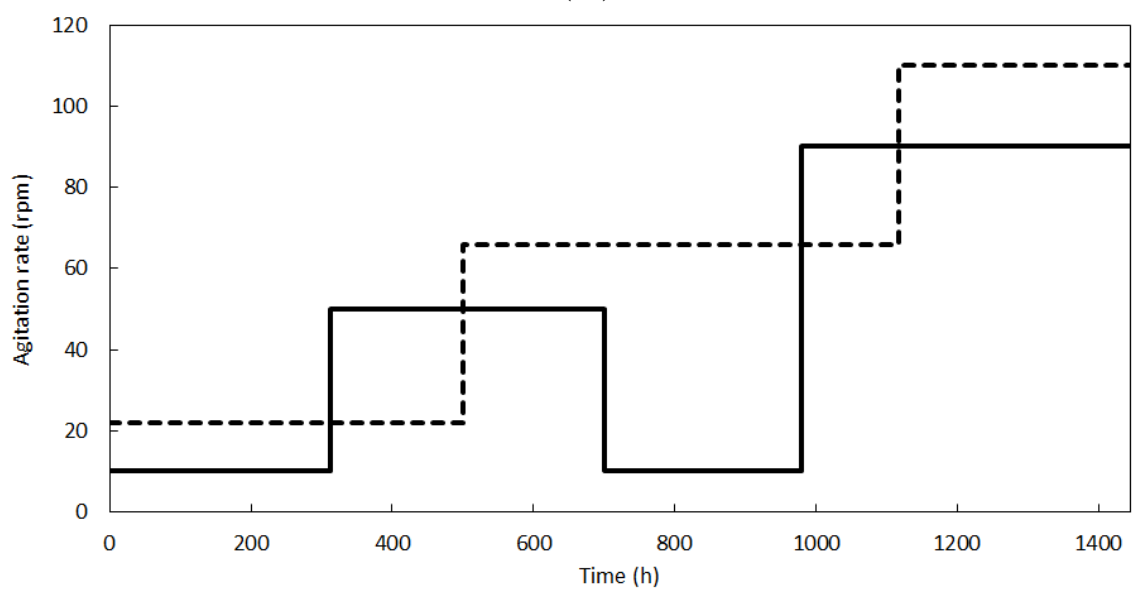

(B)

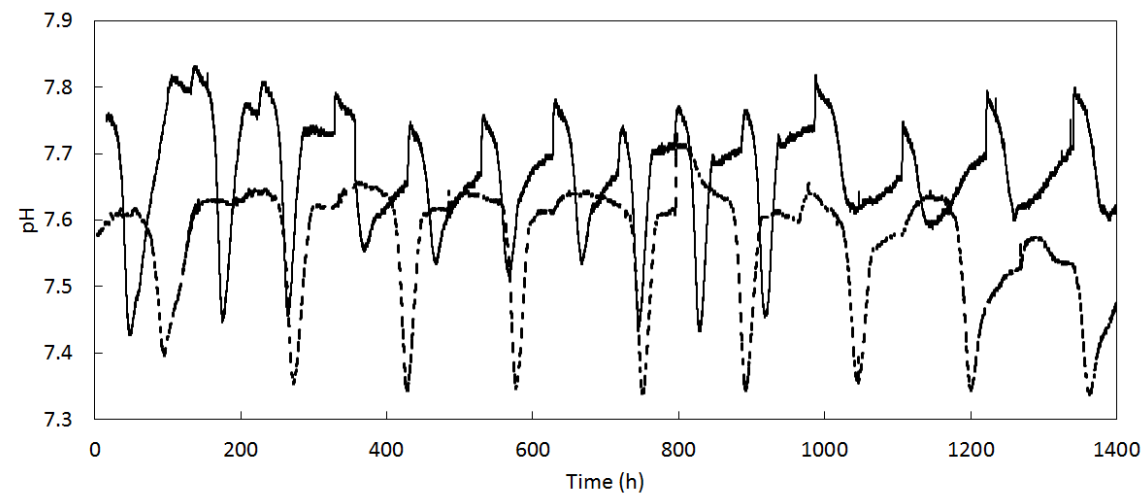

(C)

Figure 3: Temporal changes in biogas flowrate (A), agitation rate (B) and $\mathrm{pH}(\mathrm{C})$ for the helical ribbon (continuous line) and the Rushton turbine (dotted line). 
Figure 4

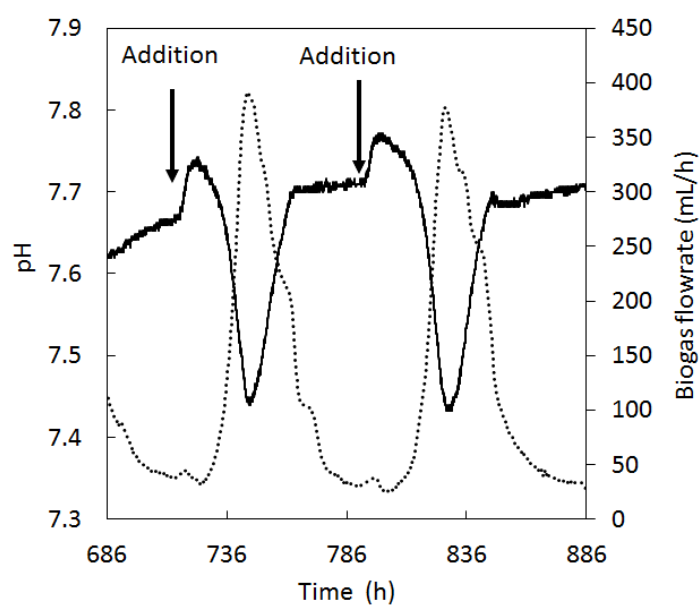

(A)

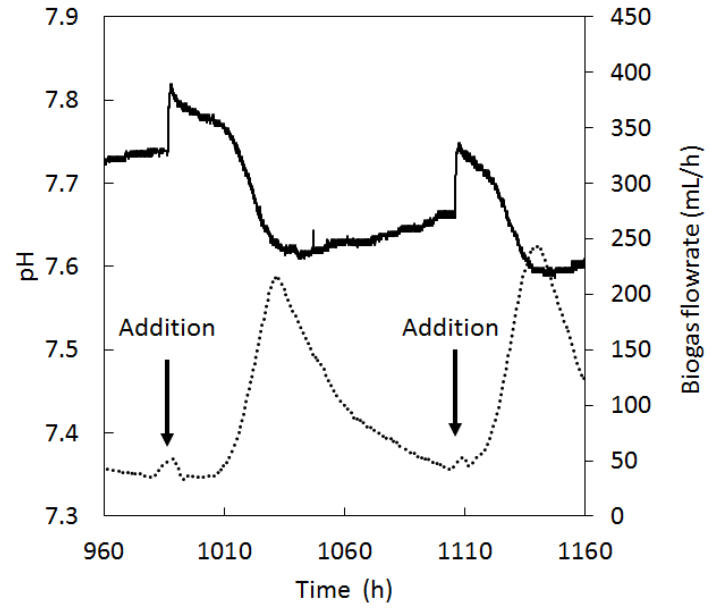

(C)

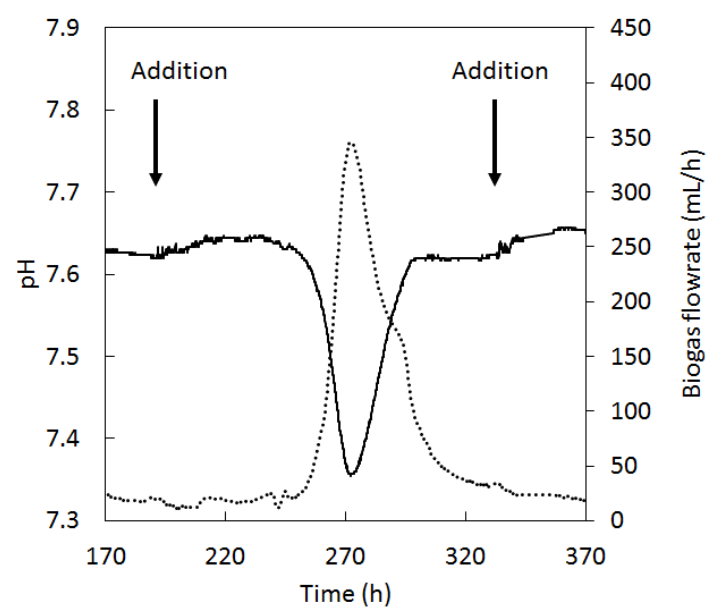

(B)

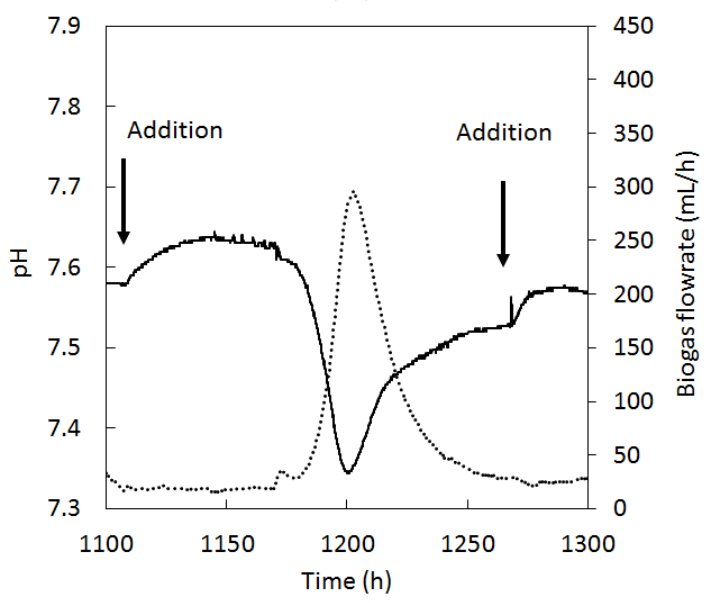

(D)

Figure 4: Focus on $\mathrm{pH}$ (continuous line) and biogas flowrate (dotted line) time variations for the helical ribbon at an agitation rate of $10 \mathrm{rpm}(\mathrm{A})$ and $90 \mathrm{rpm}(\mathrm{C})$ ) and for the Rushton turbine at an agitation rate of $22 \mathrm{rpm}$ (B) and $110 \mathrm{rpm}$ (D). Vertical arrows indicate cellulose addition in the digester. 
Figure 5

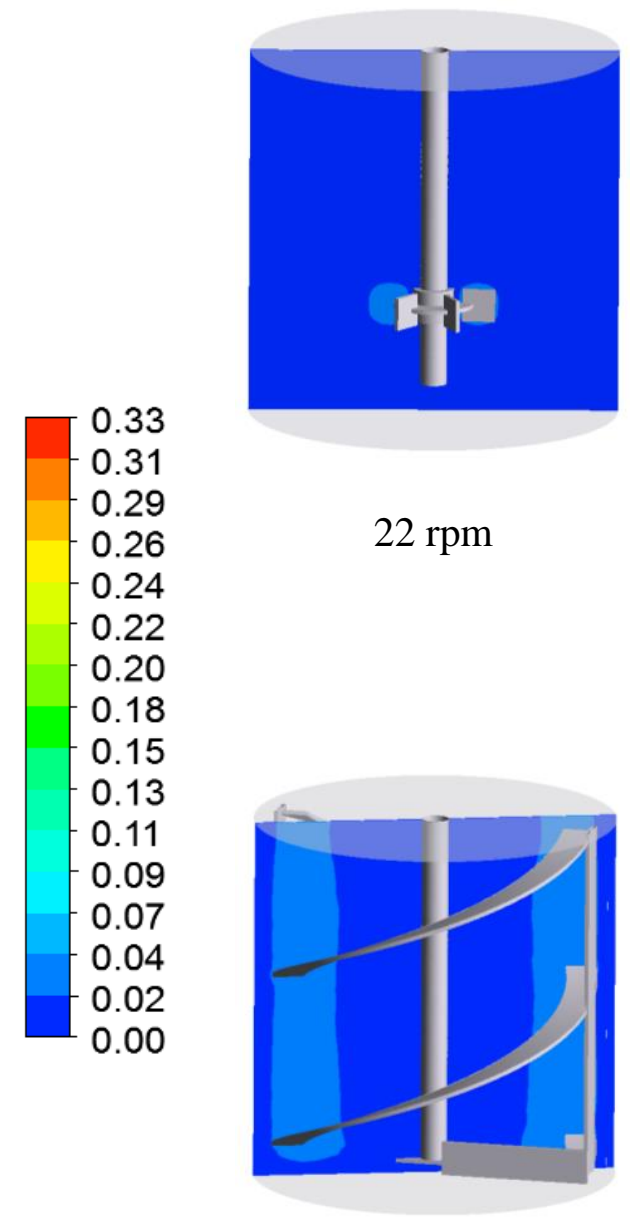

$10 \mathrm{rpm}$
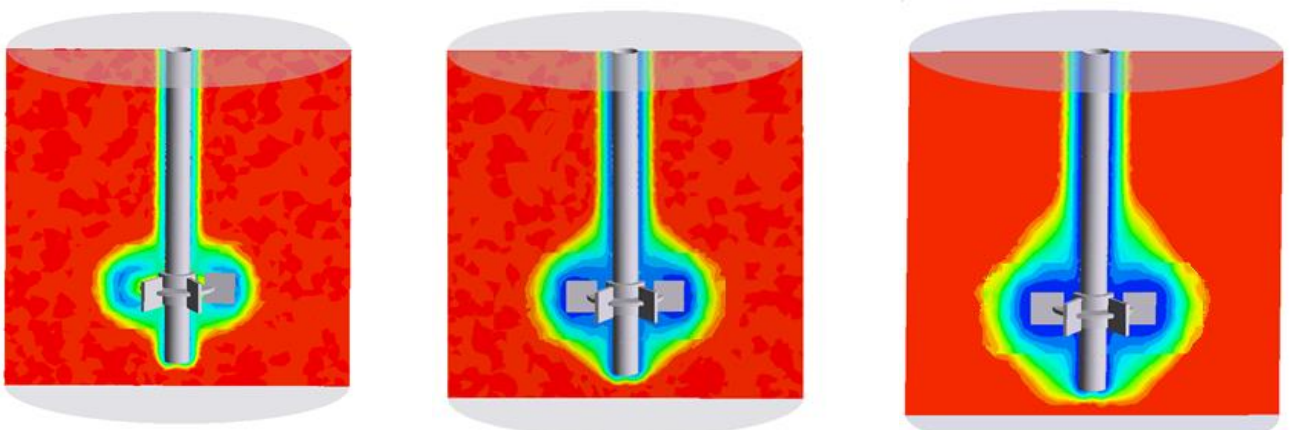


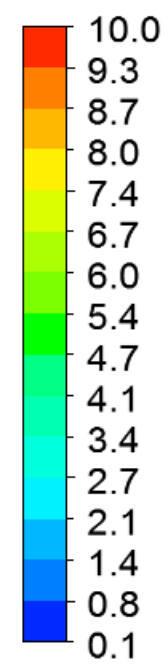

$66 \mathrm{rpm}$

$110 \mathrm{rpm}$

8.3

8.0

(C)
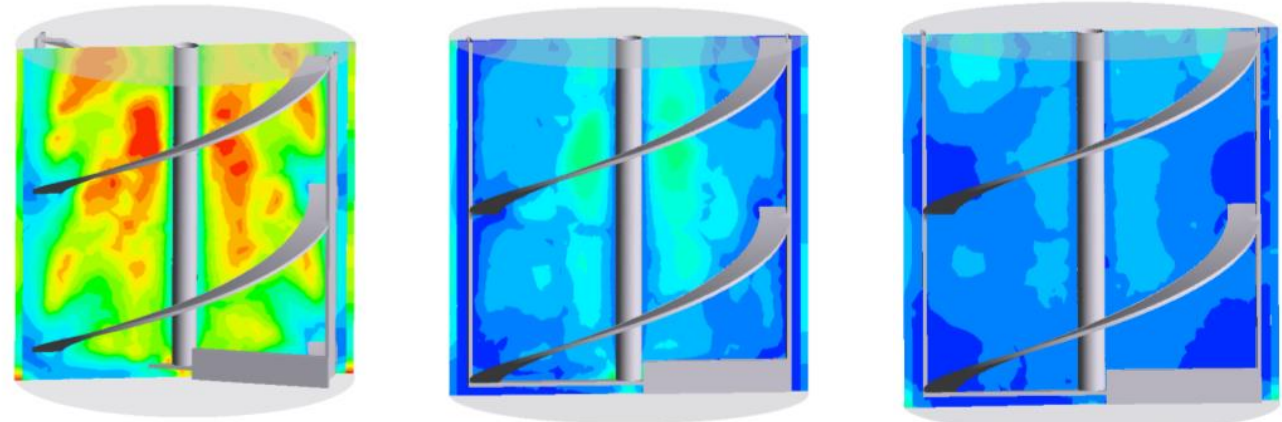

$10 \mathrm{rpm}$

$50 \mathrm{rpm}$

$90 \mathrm{rpm}$

(D)

Figure 5: CFD simulations of the impact of agitation rate on the mean velocity fields $\left(\mathrm{m} \mathrm{s}^{-1}\right)$ (A, B) and the viscosity fields (Pa s) (C, D) simulated by CFD in the digester equipped with the Rushton turbine (A, C) and the helical ribbon (B, D). 
Table 1

Table 1A: Synthesis of experimental results.

\begin{tabular}{|c|c|c|c|c|c|c|c|c|c|}
\hline Impeller & $\begin{array}{c}N \\
(\mathrm{rpm})\end{array}$ & $\begin{array}{c}\dot{\gamma}_{a}\left(\mathrm{~s}^{-1}\right) \\
\text { (Equation 4) }\end{array}$ & $\begin{array}{c}\mathrm{Re}_{\mathrm{a}} \\
\text { (Equation 6) }\end{array}$ & $\begin{array}{c}P_{\text {exp }}(\mathrm{W}) \\
\text { (Equation 3) }\end{array}$ & $\begin{array}{c}\text { Delay time } \tau \\
\text { between } \\
\text { injection and } \\
\text { production onset } \\
\text { (h) }\end{array}$ & $\begin{array}{l}\text { Production } \\
\text { duration } \\
\text { per peak } \\
\text { (h) }\end{array}$ & $\begin{array}{l}\text { Maximal } \\
\text { production } \\
\text { per peak } \\
\left(\mathrm{mL} \mathrm{h}^{-1}\right)\end{array}$ & $\begin{array}{c}\text { Time- } \\
\text { averaged } \\
\text { biogas } \\
\text { flowrate }^{1} \\
\bar{Q}\left(\mathrm{~mL} \mathrm{~h}^{-1}\right)\end{array}$ & $\begin{array}{c}\text { Mean } \mathrm{CH}_{4} \\
\text { fraction }^{2} \\
(\%)\end{array}$ \\
\hline \multirow{3}{*}{$\begin{array}{c}\text { Helical } \\
\text { ribbon }\end{array}$} & 10 & 7 & 1.7 & 0.022 & $11.2 \pm 0.6$ & $46 \pm 2$ & $380 \pm 8$ & $175 \pm 7$ & $64 \pm 1$ \\
\hline & 50 & 35 & 25.2 & 0.185 & $10.0 \pm 0.4$ & $62 \pm 6$ & $330 \pm 21$ & $141 \pm 12$ & $58 \pm 1$ \\
\hline & 90 & 63 & 67.5 & 0.402 & $8.8 \pm 2.1$ & $73 \pm 3$ & $242 \pm 5$ & $123 \pm 5$ & $57 \pm 1$ \\
\hline \multirow{3}{*}{$\begin{array}{l}\text { Rushton } \\
\text { turbine }\end{array}$} & 22 & 4.2 & 0.4 & 0.002 & $68.1 \pm 5.0$ & $50 \pm 9$ & $322 \pm 61$ & $85 \pm 6$ & $64 \pm 0$ \\
\hline & 66 & 13 & 2.6 & 0.008 & $73.3 \pm 2.6$ & $50 \pm 12$ & $388 \pm 10$ & $83 \pm 8$ & $64 \pm 1$ \\
\hline & 110 & 21 & 6.0 & 0.016 & $64.0 \pm 2.6$ & $60 \pm 11$ & $300 \pm 17$ & $82 \pm 9$ & $59 \pm 2$ \\
\hline
\end{tabular}

1. Determined over the duration of a given agitation condition.

2. This mean value was determined by averaging the $\mathrm{CH}_{4}$ fraction measured at the end of production peaks, before next cellulose addition for all peaks of a given agitation condition. 
Table 1B: Characterization of digester by CFD calculations.

\begin{tabular}{|c|c|c|c|c|c|c|c|}
\hline Impeller & $N(\mathrm{rpm})$ & $\begin{array}{c}P_{C F D}(\mathrm{~W}) \\
\text { (equation } 11)\end{array}$ & $\begin{array}{l}\text { Mixing } \\
\text { time } \\
t_{M}(\mathrm{~s})\end{array}$ & $\begin{array}{l}E_{\text {homogeneity }}(\mathrm{J}) \\
\text { (Equation } 14)\end{array}$ & $\begin{array}{c}\langle u\rangle\left(\mathrm{m} \mathrm{s}^{-1}\right) \\
\text { (Equation } 10)\end{array}$ & $\begin{array}{c}\langle\mu\rangle(\mathrm{Pa} \mathrm{s}) \\
\text { (Equation } 10)\end{array}$ & $\begin{array}{c}\text { Ratio Dead- } \\
\text { volume/Total } \\
\text { volume } \\
(\%)\end{array}$ \\
\hline \multirow{3}{*}{$\begin{array}{l}\text { Helical } \\
\text { ribbon }\end{array}$} & 10 & 0.036 & 187 & 6.6 & 0.02 & 5.2 & $<1$ \\
\hline & 50 & 0.314 & 47 & 14.8 & 0.118 & 1.8 & $<1$ \\
\hline & 90 & 0.699 & 21 & 14.0 & 0.166 & 1.0 & $<1$ \\
\hline \multirow{3}{*}{$\begin{array}{l}\text { Rushton } \\
\text { turbine }\end{array}$} & 22 & 0.002 & 11696 & 21.4 & 0.00172 & 9.6 & 68 \\
\hline & 66 & 0.010 & 4150 & 43.0 & 0.00406 & 9.5 & 91 \\
\hline & 110 & 0.022 & 2804 & 61.3 & 0.00409 & 9.3 & 91 \\
\hline
\end{tabular}

